\title{
Tracking progress towards health related millennium development goals in India
}

\section{Kumaresan Kuppusamy, Mahesh Kumari Rajarathinam}

Department of Community Medicine, Sri Muthukumuran Medical College Hospital and Research Institute, Chikkarayapuram, ${ }^{1}$ Department of Public Health and Preventive Medicine, Government Primary Health Centre, Anakaputhur,

Chennai, Tamil Nadu, India

Address for the Correspondence:

Dr. Kumaresan Kuppusamy,

Department of Community Medicine, Sri Muthukumuran

Medical College Hospital and Research Institute, Chikkarayapuram, Near Mangadu, Chennai - 600069 Tamil Nadu, India

E-mail: kumareshk99@gmail.com

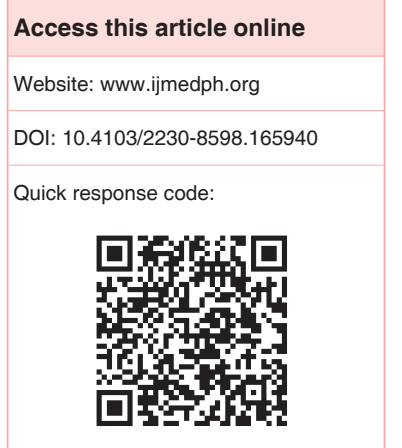

The millennium development goals (MDGs) adopted during the millennium summit in 2000 gave an opportunity to improve the health and overall development. The MDG framework had 8 goals, 21 targets, and 60 indicators. Of these, three are directly related to health and have other interrelated goals and targets that influence health. The year 1990 is baseline, and the targets are to be reached by 2015. India's progress towards health related MDGs is lagging in some areas, and more attention is needed to states and districts where the indicators are poor. The proportion of underweight children $<3$ years is around $40 \%$. The under-five and infant mortality rate is 49 and $40 / 1000$ live births in 2013 , respectively. The country lags behind the maternal mortality ratio target of 109/100,000 live births. Regarding HIV, malaria, and tuberculosis, trend reversal had been achieved while providing basic sanitation facilities remains a big challenge.

Key words: Goal 6, health, India, maternal mortality ratio, millennium development goal, under-five mortality

\section{INTRODUCTION}

The millennium development goals (MDGs), adopted during the millennium summit represented by 189 countries and further agreement in 2005 by the member states provided an opportunity for the governments to have a concerted and sustainable action to improve the health and overall development. The MDGs aimed to reduce the striking inequalities between the rich and poor countries, and between the rich and poor populations within countries. ${ }^{[1]}$ The MDGs have been widely accepted as a yardstick for measuring the development progress across the countries. ${ }^{[2]}$

The revised MDG framework consists of 8 goals, 21 targets, and 60 indicators. ${ }^{[3]}$ Of the eight goals, three are directly related to health. To reduce the child mortality (MDG 4), to improve the maternal health (MDG 5); and combat HIV / AIDS, malaria, and other diseases (MDG 6). The other goals have targets and indicators indirectly related to health. The prevalence of underweight children $<5$ years (MDG 1), proportion of population without sustainable access to safe drinking water and basic sanitation (MDG 7) and access to affordable essential drugs (MDG 8). Achieving universal primary education (MDG 2) and women empowerment (MDG 3) also influence health indicators.

The inclusion of these health related goals in the development goals underscores the inextricable connection between development and health. ${ }^{[4]}$ The significant thing in MDG is that many of the targets are specific, and indicators are measurable by the available data. The summit had set the year 1990 as baseline and 2015 as the deadline to achieve the goals, targets, and various indicators set in the MDG framework.

India, home to more than 1.2 billion population, is passing through the economic, demographic,

This is an open access article distributed under the terms of the Creative Commons AttributionNonCommercial-ShareAlike 3.0 License, which allows others to remix, tweak, and build upon the work non-commercially, as long as the author is credited and the new creations are licensed under the identical terms.

For reprints contact: reprints@medknow.com

How to cite this article: Kuppusamy K, Rajarathinam MK. Tracking progress towards health related millennium development goals in India. Int J Med Public Health 2015;5:253-8. 
and epidemiological transition. Ever since independence in 1947, various national health schemes, programs, and policies have been launched with the view to improve the health status of people. ${ }^{[5]}$ India's progress towards MDGs is crucial in attaining the goals and targets globally.

As the deadline year 2015 is reached, it assumes great significance in monitoring the progress towards health related MDGs in India. With this background, a review was done regarding the progress towards the goals directly related to health, and other interrelated indicators in MDG framework. The progress towards achieving the goals and targets is monitored by the use of available data sources at the national level and from international agencies.

\section{GOAL 1: ERADICATE EXTREME POVERTY AND HUNGER}

\section{Target 1.C: Halve, between 1990 and 2015, the proportion of people who suffer from hunger}

For this goal, the prevalence of underweight children $<5$ years of age is taken as an indicator. Under-nutrition is linked to poverty and in turn affects the overall health status and survival of the children. In view of data availability and to have a uniform comparison for trends, the prevalence of underweight children $<3$ years is taken in India.

The proportion of children underweight $<3$ years was $52.8 \%$ in $1992-1993^{[6]}$ and the target is $26 \%$. According to National Family Health Survey 3, the prevalence of underweight children was $40.4 \% .{ }^{[7]}$ The prevalence of stunting and wasting was $44.9 \%$ and $22.9 \%$ in 2005-2006, respectively. ${ }^{[7]}$ Certain states such as Mizoram, Sikkim, Manipur, Kerala, Goa, Punjab, Nagaland, and Tamil Nadu have already achieved the target, while states such as Uttar Pradesh (41.6\%), Chhattisgarh (47.8\%), Jharkhand (54.6\%), Bihar (54.9\%), and Madhya Pradesh (57.9\%) have rates above $40 \% \cdot{ }^{[7,8]}$

Strengthening of Integrated Child Development Services, proper monitoring and focus on early childhood care are needed in reducing under-nutrition among children. The nutritional status of children $<3$ years is depicted in Figure 1.

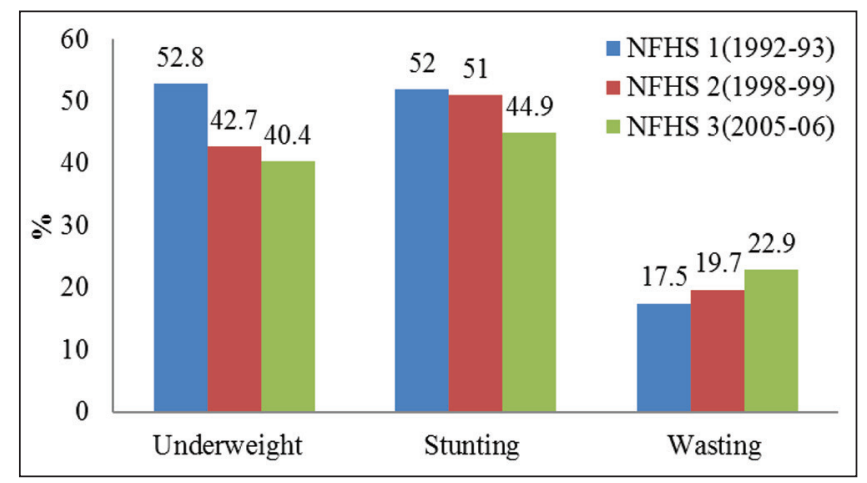

Figure 1: Nutritional status of children $<3$ years in India, source:[6-9]

\section{GOAL 4: REDUCE CHILD MORTALITY}

\section{Target 4.A: Reduce by two-third, between 1990 and 2015, the under-five mortality rate}

The indicators for monitoring child mortality are underfive mortality rate, infant mortality rate (IMR), and measles immunization coverage under 1 -year. Under-five mortality measures the probability of dying between birth and 5 years of age. It reflects the socioeconomic and environmental conditions in which they live and quality of health care they receive. Globally, 6.5 million under-five children died in 2012, compared to 12.6 million in $1990 .{ }^{[10]}$ In India, 1.4 million under-five deaths occurred in 2012. ${ }^{[10]}$ More than 50\% deaths happen in the neonatal period. The most important causes being pneumonia $(18 \%)$, preterm birth complications (14\%), acute diarrheal diseases $(12 \%)$, intrapartum-related complications ( $9 \%)$, malaria $(7 \%)$, neonatal sepsis, meningitis, tetanus, and HIV/AIDS (10\%). ${ }^{[1]}$

The under-five mortality rate had declined by $60 \%$ from $125 / 1000$ live births in 1990 to 49 in 2013..$^{[8,12]}$ The average annual rate of reduction is below $4.3 \% .{ }^{[10]}$ The under-five mortality is higher in rural areas (55) compared to urban areas (29). Among the bigger states, the lowest rate was noted in Kerala (12) and highest in Assam (73) followed by Madhya Pradesh (69). The other states with high under-five mortality are Odisha (66), Uttar Pradesh (64), Rajasthan (57), Bihar (54), and Chattisgarh (53) as per Sample Registration System (SRS) report. ${ }^{[12]}$

IMR, a major contributor of under-five mortality, is widely used as a best indicator of health and social development. According to SRS, the IMR in India is 40/1000 live births in 2013. ${ }^{[12]}$ The IMR had been cut down by half from 1990 level of 80/1000 live births. The target for the year 2015 is 27/1000 live births. Among bigger Indian states, it varies from 12 in Kerala to 54 in Assam and Madhya Pradesh. States such as Tamil Nadu (21), Delhi (24), Maharashtra (24), and Punjab (26) have attained the levels below 27/1000 live births. ${ }^{[12]}$ The trend in under-five mortality and IMR is given in Figure 2.

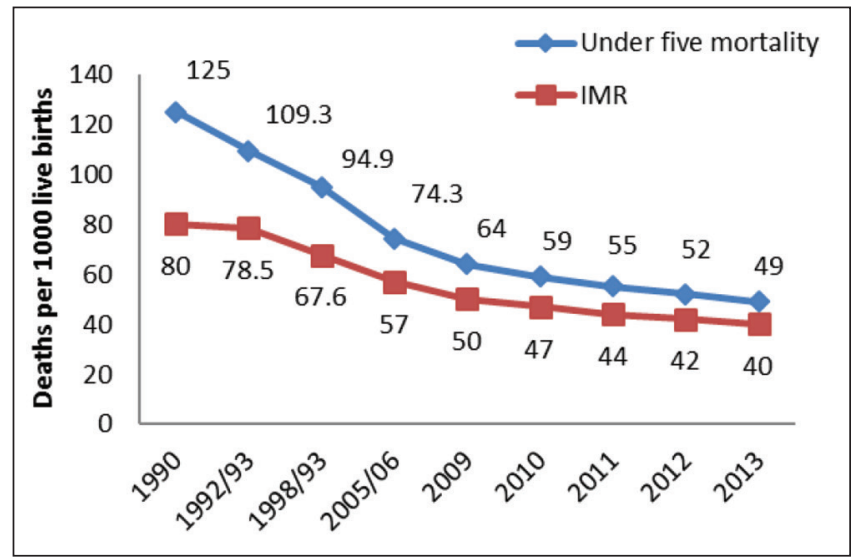

Figure 2: Trend in under-five and infant mortality rate in India, source: $[6-9,12-17]$ 
Measles is the leading cause of mortality and morbidity among vaccine preventable diseases in children. In 2013, about 15,768 cases of measles and 10 deaths were reported in India. ${ }^{[18]}$ The percentage of 1-year-old children (12-23 months) immunized against measles had increased from $42.2 \%$ in $1992-1993^{[6]}$ to $74.1 \%$ in $2009 .{ }^{[19]}$

Various measures like setting up of special newborn care units at district hospitals and medical colleges, newborn stabilization units at community health centers, promotion of home based newborn care, and schemes like Navjat Shishu Suraksha Karyakram are taken by Government of India under National Health Mission to reduce the under-five deaths. Training is also provided for health workers in integrated management of neonatal and childhood illness.

\section{GOAL 5: IMPROVE MATERNAL HEALTH}

\section{Target 5.A: Reduce by three-quarters, between 1990 and 2015, the maternal mortality ratio}

Maternal mortality ratio (MMR) is used as the best indicator for improving the maternal health. The estimated 1990 value was 437/100,000 live births, and the current MMR is $167 / 100,000$ livebirths during 2011-2013, with the majority happening in 20-24 years age group. ${ }^{[20]}$ India had achieved around $62 \%$ reduction toward the target of 109 by 2015, and the average annual rate of reduction is $5.5 \% .{ }^{[10]}$ Wide variations exist among the states, with Kerala having lowest MMR of 61, followed by Maharashtra (68), Tamil Nadu (79), and Assam having maximum maternal deaths of 300 per lakh. The states such as Uttar Pradesh (285), Rajasthan (244), Odisha (222), Madhya Pradesh/Chhattisgarh (221), and Bihar/Jharkhand (208) have high maternal deaths when compared to other states. ${ }^{[20]}$ The trend in maternal mortality is given in Figure 3.

Promoting institutional deliveries and assistance by trained health personnel are key interventions to reduce maternal deaths. The proportion of births attended by skilled health personnel is used as process indicator to improve maternal health. Although the target is to achieve universal coverage $(100 \%)$, the percentage of

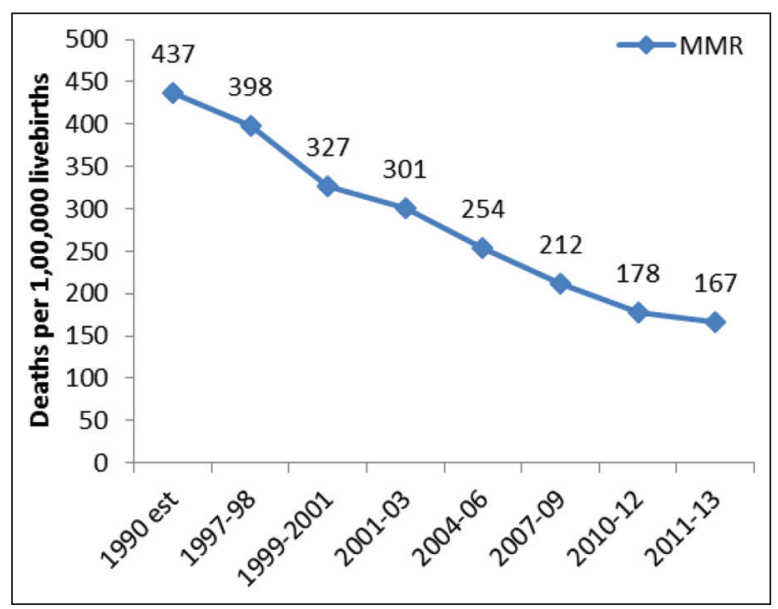

Figure 3: Trend in maternal mortality ratio in India, source:[8,20-23] deliveries attended by skilled health personnel had increased over the years from $34 \%$ in $1992-1993^{[6]}$ to $76.2 \%$ in $2009 .{ }^{[19]}$

\section{Target 5.B: Achieve, by 2015 universal access to reproductive health}

To reduce the number of maternal deaths women need access to good quality reproductive health services including family planning. ${ }^{[4]}$ To achieve this target, four indicators are used to analyze the access to reproductive health services. The contraceptive prevalence rate had increased from $40.7 \%$ in $1992-1993^{[6]}$ to $54.8 \%$ in $2007-2008 .{ }^{[24]}$ The unmet need for family planning is about $14.4 \% .{ }^{[24]}$ Regarding antenatal care coverage, the percentage of pregnant women who had three or more visits increased from $43.9 \%$ to $68.7 \%$, between $1992 / 93$ and $2009,{ }^{[6,19]}$ and those who had at least one antenatal check-up is around $86.9 \%$ in $2009 .{ }^{[19]}$ The adolescent fertility rate per 1000 girls aged $15-19$ years is about $39 .{ }^{[10]}$

The provision of good quality basic and emergency obstetric care coupled with proper referral services will bring down the maternal deaths. Initiatives such as mother-child tracking system, maternal death review, and cash assistance schemes such as Janani Surksha Yojana and Janani Shishu Suraksha Karyakram are the steps in the right direction to improve the maternal health.

\section{GOAL 6: COMBAT HIV/AIDS, MALARIA, AND OTHER DISEASES}

\section{Target 6.A: Have halted by 2015 and begun to reverse the spread of HIV/AIDS}

Around 2.1 million live with HIV/AIDS in India (2011), with 86\% in $15-49$ years age group and 39\% were women. India has demonstrated an overall reduction of $57 \%$ in estimated annual new HIV infections during the past decade from 2.74 lakh in 2000 to 1.16 lakh in 2011. ${ }^{[25]}$ The indicators used are HIV prevalence among population aged 15-24 years, condom use at last high-risk sex, proportion of population aged 15-24 years with comprehensive correct knowledge of HIV/AIDS and children orphaned due to HIV/AIDS.

The HIV prevalence among 15-24 years population declined from around $0.30 \%$ in 2001 to $0.11 \%$ in 2011 . At the same time, the prevalence among adults (15-49 years) also declined from $0.41 \%$ to $0.27 \%$, between 2001 and 2011. ${ }^{[25]}$ The high prevalence states are Nagaland, Mizoram, Manipur, Andhra Pradesh, Karnataka, Maharashtra, Tamil Nadu, Goa, and Gujarat. HIV/AIDS is concentrated mainly among the high-risk groups, $2.59 \%$ among truck drivers, female sex workers (2.67\%), Men having sex with men (4.43\%), Injecting drug users $(7.14 \%)$, and $8.82 \%$ among transgenders. ${ }^{[25]}$

The proportion of population aged 15-24 years who used a condom during last sex with nonregular partner registered a 19\% increase from $51.9 \%$ in 2001 to $61.7 \%$ in 2006. According to Behavioral Surveillance Survey (BSS) 2006, the national estimate for the proportion of population aged 15-24 years with comprehensive correct knowledge of HIV/AIDS in 2006 was $32.9 \%$ reporting 
betterment from 2001 (22.2\%). ${ }^{[8]}$ Regarding access to antiretroviral therapy, about 7.68 lakh people living with HIV receive free antiretroviral drugs from 425 ART centers ${ }^{[25]}$ and the coverage among people eligible for treatment is $50 \%{ }^{[10]}$

The interventions under national AIDS control program and various other strategies had caused a considerable decline in HIV prevalence and increased in knowledge regarding HIV/AIDS. Intensified information, education, communication campaigns, and condom promotion, providing more testing and counselling facilities added with scaling up of targeted interventions for high-risk groups along with care, support, and treatment for the people living with HIV will further reverse the trend of HIV/AIDS.

\section{Target 6.C: Have halted by 2015 and begun to reverse the incidence of malaria and other major diseases}

\section{Malaria}

The indicators used were incidence and death rates associated with malaria and the proportion of under-five children using insecticide-treated bednets and fever treated with appropriate antimalarial drugs. The total number of malaria cases reduced by over $70 \%$ between 1995 and 2013 and the annual parasite incidence is $0.21 / 1000$ population in $2013 .{ }^{[26,27]}$ The proportion of under-five children with fever who received treatment with any antimalarial drugs is only $8 \%{ }^{[10]}$ Rapid detection of cases and treatment using effective antimalarials (Artemisinin Combination Therapy) along with the use of insecticide-treated bednets and other integrated vector control methods will reduce the burden of malaria. Malaria situation in India is given in Table 1.

\section{Tuberculosis}

Tuberculosis (TB) remains a major global health problem, responsible for ill-health among millions of people each year. ${ }^{[28]}$ The indicators under MDG are TB incidence, prevalence, and mortality rates; case detection rate and treatment success rate among smear-positive cases.

India, a high TB burden country accounts for about 2 million cases annually. The prevalence had reduced by around $55 \%$ from 465/100,000 in 1990 to 211/100,000 in 2013 and incidence had fallen to $171 / 100,000$ from 216 in $1990 . .^{[8,28]}$ The mortality due

\begin{tabular}{lcccc} 
Table 1: Malaria situation in India \\
\hline Year & $\begin{array}{c}\text { Total malaria } \\
\text { cases } \\
\text { (millions) }\end{array}$ & $\begin{array}{c}\text { Plasmodium } \\
\text { falciparum } \\
\text { cases (millions) }\end{array}$ & $\begin{array}{c}\text { Total } \\
\text { deaths }\end{array}$ & $\begin{array}{c}\text { Annual parasite } \\
\text { incidence (per } \\
\mathbf{1 0 0 0} \text { population) }\end{array}$ \\
\hline 1995 & 2.93 & 1.14 & 1151 & 3.29 \\
2000 & 2.03 & 1.05 & 932 & 2.09 \\
2005 & 1.82 & 0.81 & 963 & 1.68 \\
2010 & 1.60 & 0.83 & 1018 & 1.37 \\
2011 & 1.31 & 0.67 & 754 & 1.10 \\
2012 & 1.06 & 0.53 & 519 & 0.88 \\
2013 (P) & 0.84 & 0.46 & 379 & 0.21 \\
\hline
\end{tabular}

Source $^{[26,27]}$ to TB is also cut by $50 \%$ between 1990 and 2013. ${ }^{[28]}$ In a study in South India, the annual risk of TB infection varies between $1.2 \%$ and $1.6 \%$ with an average decline of $5.8 \%$ /year. ${ }^{[2]}$ The TB burden in India is given in Figure 4.

After the implementation of revised national TB control program and DOTS strategy, the case detection rate had crossed $70 \%$ since 2007 from 1999 level of 44\%, while the treatment success rate had increased from 82\% in 1999 to $88 \%$ in 2013 among the new sputum smear-positive cases. ${ }^{[27,28,30]}$

The main area of concern is the increase in multidrug-resistant cases (MDR-TB) and HIV-TB combination. The prevalence of MDR-TB is $2.2 \%$ among new cases, and $15 \%$ among retreatment cases and the HIV prevalence is $5.7 \%$ among incident cases. ${ }^{[28]}$ Steps such as making TB as a notifiable disease, online patient tracking system, more involvement of private providers, addressing $\mathrm{HIV} / \mathrm{TB}$ combination, and better program management will help in TB control.

\section{GOAL 7: ENSURE ENVIRONMENTAL SUSTAINABILITY}

\section{Target 7.C: Halve, by 2015, the proportion of people without sustainable access to safe drinking water and basic sanitation}

Drinking water quality and basic sanitation form a major determinant of people's health. In rural areas, the proportion of population using an improved source of drinking water had increased from an estimated 1990 level of 64\% to $91 \%$ in 2012, and in urban areas the coverage is $97 \%$ (2012) up from $89 \%$ in $1990 .{ }^{[31]}$ India had met the MDG target of sustainable access to safe drinking water to its population.

A huge gap exists in the availability and accessibility for basic sanitation facilities. In 2012, the proportion of people using an improved sanitation facility was better in urban areas (60\%) compared to the lower level of $25 \%$ in rural areas. ${ }^{[31]}$ Although some progress had been made, but India is still clearly behind the target of providing better sanitation facilities to the people. The recently launched Swachh

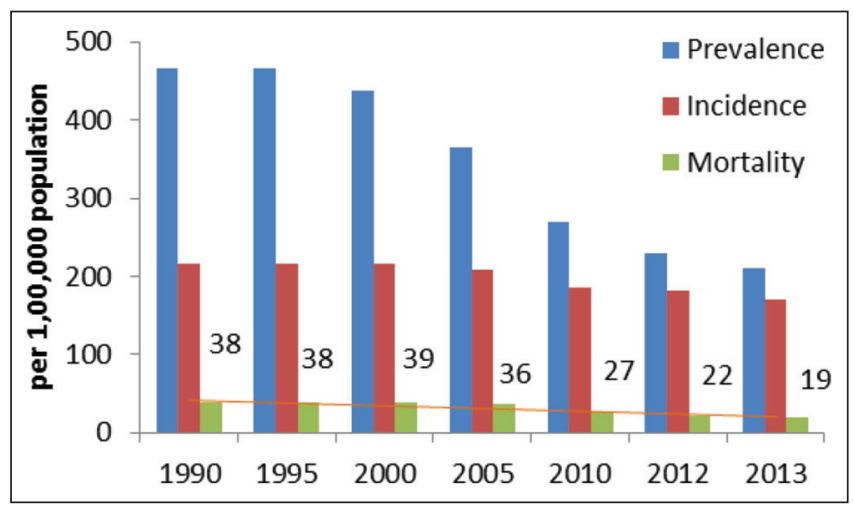

Figure 4: Tuberculosis burden in India, source:[8,28] 
Table 2: Health related millennium development goals in India

Goal 1: Eradicate extreme poverty and hunger

Target 1.C: Halve, between 1990 and 2015, the proportion of people who suffer from hunger

Status: Slow or almost off track

Goals/Targets/Indicators

1990/estimated levels Target for 2015

Current levels

Prevalence of underweight children below 3 years of age (\%)

52.8

26

$40.4(2005-2006)$

Goal 4: Reduce child mortality

Target 4.A: Reduce by two-third, between 1990 and 2015, the

under-five mortality rate

Status: Moderately on track due to sharp decline in recent years

Under-five mortality rate (per 1000 live births)

Infant mortality rate (per 1000 live births)

Proportion of 1-year-old children immunized against measles (\%)

125

Goal 5: Improve maternal health

Target 5.A: Reduce by three-quarters, between 1990 and 2015, the maternal mortality ratio

Status: Slow or off track

Maternal mortality ratio (per 100,000 live births)

Proportion of births attended by skilled health personnel (\%)

Target 5.B: Achieve, by 2015 universal access to reproductive health

Contraceptive prevalence rate $(\%)$

Adolescent birth rate per 1000 girls aged $15-19$ years

Antenatal care coverage, three or more (\%)

Unmet need for family planning (\%)

Goal 6: Combat HIVIAIDS, malaria, and other diseases

Target 6.A: Have halted by 2015 and begun to reverse the spread of HIVIAIDS

Status: On track as trend reversal in HIV prevalence has achieved HIV prevalence among population aged $15-24$ years (\%)

HIV prevalence among 15-24 years old pregnant women (\%)

Condom use at last high-risk sex (\%)

Proportion of population aged 15-4 years with comprehensive correct knowledge of HIVIAIDS (\%)

Target 6.C: Have halted by 2015 and begun to reverse the incidence of malaria and other major diseases

Status: Moderately on track as trend reversal has achieved for

Annual Parasite Incidence and for prevalence of TB

Annual parasite incidence (per 1000 population)

Malaria death rate (per 100,000 population)

Malaria incidence rate (per 100,000 population)

Tuberculosis prevalence rate per 100,000

Tuberculosis death rate per 100,000

NSP case detection rate $(\%)$

Treatment success rate (\%)

Goal 7: Ensure environmental sustainability

Target 7.C: Halve, by 2015, the proportion of people without sustainable access to safe drinking water and basic sanitation

Status: Met for indicator of drinking water, but slow for indicator of basic sanitation

Proportion of population using an improved drinking water source (\%)

Rural

Urban

Total

Proportion of population using an improved sanitation facility (\%)

Rural

Urban

Total

Source. ${ }^{[6-8,8,10,12,18-20,24-32]} \mathrm{NSP}$ : New smear positive
80

42.2

$\begin{array}{ccc}3.29(1995) & \text { Target } & 0.21(2013) \\ 0.13(1995) & \text { is trend } & 0.038(2013) \\ 330(1995) & \text { reversal } & 69(2013) \\ 465 & & 211(2013) \\ 38 & & 19(2013) \\ 44(1999) & 67(2013) \\ 82(1999) & & 88(2013)\end{array}$

$\begin{array}{lcc}0.30(2001) & \begin{array}{c}\text { Target is trend } \\ \text { reversal }\end{array} & 0.11(2011) \\ 51.9(2001) & & 0.39(2011) \\ 22.2(2001) & & 61.7(2006) \\ & & 32.9(2006)\end{array}$

$54.8(2007-2008)$

$39(2006-2012)$

$68.7(2009)$

$14.4(2007-2008)$

43.9

19.5

109

167 (2011-2013)

$76.2(2009)$

40.7

49 (2013)

$74.1(2009)$

$\begin{array}{ccc}437 & 109 & 167(2011-2013) \\ 34 & 100 & 76.2(2009) \\ 40.7 & & 54.8(2007-2008) \\ 50 & & 39(2006-2012) \\ 43.9 & 68.7(2009) \\ 19.5 & & 14.4(2007-2008)\end{array}$

$32.9(2006)$

88 (2013) 
Bharat Mission needs to be in a fast track mode to achieve this target.

\section{GOAL 8: DEVELOP A GLOBAL PARTNERSHIP FOR DEVELOPMENT}

\section{Target 8.E: In cooperation with pharmaceutical companies, provide access to affordable essential drugs in developing countries}

The indicator used is the proportion of the population with access to affordable essential drugs on a sustainable basis. As per world health statistics 2014, the median availability of selected generic medicines is $22.1 \%$ in the public sector and $76.8 \%$ in the private sector. ${ }^{[10]}$ Increasing the availability of essential drugs in the public sector and universal access will help to reduce the out of pocket spending and utilization of health services.

The progress toward the health related MDGs-baseline levels, the targets for 2015 and current status is given in Table 2:

\section{CONCLUSION}

MDGs had given an opportunity to deliver the results in a timeframe and helped to track the performance of health systems and programs. Although considerable progress have been made in attaining the goals, still lot more attention is needed to the goals and targets that are lagging behind. In India, large-scale interstate and intrastate disparities exist, and the progress depends on the performance of the poorly performing states and districts. A specific package of interventions and innovative strategies is needed to these states and districts and perhaps to even lower levels, that is, block and village levels to reach the goals and targets set out in the millennium declaration.

\section{Financial support and sponsorship}

Nil.

\section{Conflicts of interest}

There are no conflicts of interest.

\section{REFERENCES}

1. Child Mortality Coordination Group. Tracking progress towards the Millennium Development Goals: Reaching consensus on child mortality levels and trends. Bull World Health Organ 2006;84:225-32.

2. Ram F, Mohanty SK, Ram U. Progress and Prospects of Millennium Development Goals in India. Mumbai: International Institute for Population Sciences; 2009.

3. Millennium Development Goals Indicators. United Nations Statistical Division. Available from: http://www.mdgs.un.org/unsd/mdg/Host. aspx?Content=Indicators/OfficialList.htm. [Last accessed on 2015 Jan 08].

4. Singh PK. Progress in health-related millennium development goals in the WHO South-East Asia Region. Indian J Public Health 2012;56:259-68.

5. Nath A. India's progress toward achieving the Millennium Development Goals. Indian J Community Med 2011;36:85-92.

6. International Institute for Population Sciences (IIPS). National Family Health Survey (MCH and Family Planning), India 1992-93. Bombay: IIPS; 1995

7. International Institute for Population Sciences (IIPS) and Macro
International. National Family Health Survey (NFHS-3), 2005-06, India. Vol. 1. Mumbai: IIPS; 2007.

8. Millennium Development Goals, India Country Report 2014. Social Statistics Division. Ministry of Statistics and Programme Implementation. Government of India; 2014.

9. International Institute for Population Sciences (IIPS) and ORC Macro. National Family Health Survey (NFHS-2), 1998-99, India. Mumbai: IIPS; 2000.

10. World Health Organization. World Health Statistics 2014. Geneva: WHO; 2014. Available from: http://www.who.int/gho/publications/world_health_ statistics/2014. [Last assessed on 2015 Jan 08].

11. Park K. Epidemiology of communicable diseases. In: Park's Textbook of Preventive and Social Medicine. $22^{\text {nd }}$ ed. Jabalpur: M/S Banarsidas Bhanot Publishers; 2011. p. 530.

12. Sample Registration System. SRS Bulletin. Vol 49, Sep 2014. Office of Registrar General India; 2014.

13. Sample Registration System. SRS Bulletin. Vol 48, Sep 2013. Office of Registrar General India; 2013.

14. Sample Registration System. SRS Bulletin. Vol 47, Oct 2012. Office of Registrar General India; 2012.

15. Sample Registration System. SRS Bulletin. Vol 46, Dec 2011. Office of Registrar General India; 2011.

16. Sample Registration System. SRS Bulletin. Vol 45, Jan 2011. Office of Registrar General India; 2011.

17. SRS Statistical Reports. Sample Registration System. Office of Registrar General; India. Available from: http://www.censusindia.gov.in/vital_ statistics/SRS_Statistical_Report.html. [Last accessed on 2015 Jan 29].

18. National Health Profile of India 2013. Central Bureau of Health Intelligence, DGHS, Government of India; 2013. Available from: http://www.cbhidghs. nic.in/writereaddata/mainlinkFile/Health\%20Status\%20Indicators-2013. pdf. [Last accessed on 2014 Dec 10].

19. UNICEF. Coverage Evaluation Survey 2009. UNICEF India Country Office; 2009. Available from: http://www.unicef.org/india/National_Fact_ Sheet_CES_2009.pdf. [Last assessed on 2015 Jan 08].

20. MMR Bulletin, 2011-13. Sample Registration System. Office of Registrar General India. Available from: http://www.censusindia.gov.in/vital_ statistics/mmr_bulletin_2011-13.pdf. [Last accessed on 2015 Jan 31].

21. Special Bulletin on Maternal Mortality in India 2007-09. Sample Registration System. Office of Registrar General, India; June, 2011.

22. Special Bulletin on Maternal Mortality in India 2010-12. Sample Registration System. Office of Registrar General, India; December, 2013.

23. Sample Registration System. Office of Registrar General, India. Available from: http://www.censusindia.gov.in//. [Last accessed on 2015 Jan 29].

24. International Institute for Population Sciences (IIPS). District Level Household and Facility Survey (DLHS-3), 2007-08, India: Key Indicators: States and Districts. Mumbai: IIPS; 2010.

25. Annual Report 2013-14. Department of AIDS Control, Ministry of Health and Family Welfare, Government of India; New Delhi.

26. National Vector Borne Disease Control Programme; Malaria: Magnitude of the Problem. Available from: http://www.nvbdcp.gov.in/malaria3.html//. [Last accessed on 2015 Jan 10].

27. Annual Report 2013-14. Department of Health and Family Welfare. Ministry of Health and Family Welfare. Government of India. Available from: http:// www.mohfw.nic.in/index1.php?!. [Last accessed on 2015 Jan 03].

28. World Health Organization (WHO). Global Tuberculosis Report 2014. Geneva: World Health Organization; 2014.

29. Gopi PG, Subramani R, Narayanan PR. Trend in the prevalence of TB infection and ARTI after implementation of a DOTS programme in south India. Int J Tuberc Lung Dis 2006;10:346-8.

30. Central TB Division. TB India, 2011. RNTCP Annual Status Report. New Delhi: Central TB Division, DGHS; Ministry of Health and Family Welfare, GOI; 2010.

31. Central TB Division. TB India, 2014. RNTCP Annual Status Report. New Delhi: Central TB Division, DGHS; Ministry of Health and Family Welfare, GOI; 2014

32. WHO/UNICEF Joint Monitoring Programme for Water Supply and Sanitation. Progress on Drinking Water and Sanitation. 2014 Update. New York: UNICEF and World Health Organization; 2014. 